\title{
Fácies e associações de fácies de diamictitos do Subgrupo Itararé (Paleozóico superior) no norte de Santa Catarina e sul do Paraná, Bacia do Paraná, Brasil
}

\author{
José Roberto Canuto ${ }^{1}$, Paulo Roberto dos Santos $^{1} \&$ Antonio Carlos Rocha-Campos ${ }^{1}$
}

\begin{abstract}
Resumo Diamictitos glaciais fornecem evidências sobre ambientes deposicionais associados à glaciação. Entretanto, características similares apresentadas por outros sedimentos podem levar à interpretação errônea de diamictitos, pois qualquer tipo sedimentar pode ser depositado por geleira. Além disso, diagênese, compactação e perda d'água e intemperismo podem obliterar feições diagnósticas. Portanto, a maior parte dos problemas de interpretação de sucessões glaciais deverá ser esclarecida juntamente com os relacionados à origem dos diamictitos, a partir da identificação de fácies sedimentares. As fácies identificadas são: diamictito maciço compactado, diamictito deformado, diamictito maciço não compactado, diamictito tabular, diamictito lenticular, diamictito laminado com lentes de diamictito maciço, diamictito laminado rico em clastos; diamictito estratificado por variação textural ou intercalações de outras litologias, diamictito interestratificado com litologias diversas contendo icnofósseis; ritmito de diamictito e folhelho. As fácies devem ser interpretadas em termos ambientais através das relações com suas vizinhas e, para tanto, devem ser agrupadas em associações admitidas como geneticamente relacionadas. Um ambiente sedimentar será determinado mais seguramente associando-se fácies comuns a uma ou mais fácies diagnósticas que possam estar presentes, podendo ser incluídas, na análise, biofácies, se estas forem identificadas. Assim sendo, as fácies consideradas são aqui agrupadas em associações de acordo com o relacionamento observado em suas ocorrências, considerando-se a influência glacial na área do estudo no contexto terrestre, marinho de plataforma proximal e marinho de plataforma distal. Assim, foram definidas: associação de geleira aterrada terrestre, associação de geleira aterrada em plataforma proximal e associação de plataforma distal.
\end{abstract}

Palavras-chave: Subgrupo Itararé, Glaciação Permocarbonífera, Análise de fácies, Associações de fácies, Estratigrafia de Seqüências.

\begin{abstract}
Diamictite facies and facies associations of the Itararé Subgroup (Upper Paleozoic) in northern Santa Catarina and southern Paraná states, Paraná Basin, Brazil. Glacial diamictites provide information about glacial depositional environments. Similar characteristics found in other sediments, however, may lead to incorrect interpretation of diamictites since any sedimentary type can be deposited by glaciers. In addition diagenesis, compaction, water loss and weathering may obliterate diagnostic features. Most of the problems of interpretation of glacial sucessions must therefore be classified together with those related to the origin of the diamictites using the identification of sedimentary facies. These facies are compact massive diamictite; deformed diamictite; non compact massive diamictite; tabular diamictite; lenticular diamictite; laminated diamictite with massive diamictite lenses; clast rich massive diamictite; stratified diamictite with textural variation or intercalations of other rock types; diamictite with intercalations of various rock types containing icnofossils; and rhythmite of diamictite and shale. This approach was based in the interpretation of such facies in order to identify their paleoenvironmental setting. The diamictite facies were thus combined into facies associations or groups of facies genetically related, and with environmental significance. In regard to the fact that the interpretation of a sedimentary environment can rest on the association of universal facies with other diagnostic facies, their groups here recognized took into account those produced under specific depositional conditions related to the admitted glacial terrestrial and glacial-marine influences in the study area. So, terrestrial grounded glacier association, proximal platform grounded glacier association and distal platform association were defined.
\end{abstract}

Keywords: Itararé Subgroup, Permocarboniferous Glaciation, Facies analysis, Facies associations, Sequence Stratigraphy.

INTRODUÇÃO Diamictitos glaciais fornecem evidências sobre ambientes sedimentares associados a glaciações, sendo, porém, não raro, interpretados erroneamente (Eyles \& Januszczak 2004), pois outros sedimentos têm características similares e depósitos glaciais "não seguem as leis sedimentológicas e, do ponto de vista sedimentológico, qualquer tipo de sedimento pode ser depositado por uma geleira (Dreimanis 
1988)". Adicionalmente, no caso de diamictitos, diagênese, compactação e perda de água e intemperismo podem obliterar feições diagnósticas.

Com efeito, a maior parte dos problemas relacionados à interpretação de sucessões glaciais deverá ser esclarecida juntamente com os problemas relacionados à origem dos diamictitos. Tais rochas ainda continuam a ser simplisticamente descritas como tilitos, frequentemente com uma admissão implícita de que o agente direto da deposição foi o gelo de geleira. De fato, e a despeito do conhecimento de que litofácies maciças não caracterizam unicamente ambientes subglaciais, a suposição de que diamictitos indicam, necessariamente, deposição subglacial de geleira aterrada ainda pode ser encontrada na literatura (Eyles \& Januszczak 2004).

O conhecimento obtido, através da consulta da volumosa bibliografia disponível, auxiliou na identificação de feições e critérios úteis para a definição de fácies e ambientes e modelos sedimentares de diamictitos associados à glaciação, incluindo os do Itararé.

Exames detalhados de campo e laboratório têm demonstrado que diamictitos "maciços" revelam muitas estruturas que auxiliam em sua diagnose. Muitos diamictitos depositados na base do gelo, por exemplo, aparentemente maciços, quando examinados em testemunhos e pequenos afloramentos, na realidade apresentam estruturas distintivas e diagnósticas. Atualmente, e graças a evidências tais como deformação do substrato, litofácies associadas e originadas durante o fluxo da geleira sobre o sítio deposicional e à associação com discordâncias regionais, existem suficientes critérios diagnósticos para a identificação de litofácies de diamictitos, depositados na base de geleiras, ativas ou estagnadas (e.g., Boulton et al. 2001).

Fora dos ambientes de gelo aterrado, espessas sucessões de diamictitos são depositadas em ambientes lacustres e marinhos influenciados glacialmente. Estes diamictitos ocorrem em uma sucessão harmônica com as litofácies características desses ambientes, e são de grande importância para a interpretação (Anderson et al. 1991).

$\mathrm{O}$ entendimento dos processos sedimentares associados à deposição glacial, principalmente no âmbito glácio-marinho, beneficiou-se de investigações sobre mecanismos de deslizamentos, escorregamentos e fluxos gravitacionais de sedimentos, cujos processos atuam na margem continental da Antártica (e.g. Kellog \& Kellog 1981; Benn \& Evans 1998; Shanmugam 2000).

Na Bacia do Paraná, a identificação de tilitos depositados na base de geleiras baseia-se nas relações estratigráficas e, principalmente, na textura maciça da matriz. Feições de tilitos subglaciais, entretanto, assemelham-se às de outros diamictitos (e.g. depósitos de fluxo de massa, diamictitos marinhos "maciços", do tipo "rain-out", e diamictitos de fluxo). Visser (1983), por exemplo, sugeriu que muitos diamictitos maciços foram erroneamente interpretados como subglaciais e, embora tilitos de alojamento tenham sido identificados no neopaleozóico da Bacia do Karoo, as evidências para essa interpretação são precárias. Assim sendo, a identificação baseada nos critérios normalmente utili- zados, tais como, em relações estratigráficas e caráter da matriz, são insuficientes.

A classificação de fácies de diamictitos proposta neste artigo corresponde a uma abordagem sistemática e descritiva para identificar e interpretar processos e condições de deposição de diamictitos do Subgrupo Itararé da Bacia do Paraná. Compõe uma versão aprimorada daquelas apresentadas por Canuto (1985), Canuto (1993) e Canuto et al. (2001), contendo uma característica adicional extremamente importante por apresentar um enfoque prático de campo, baseado em litologias, texturas, estruturas sedimentares, alinhamento de clastos, cores, geometria, extensão, e, em alguns casos, na presença de icnofósseis, microfósseis invertebrados e de conteúdo palinológico.

Além da identificação de fácies, como acima discutido, foi elaborado um programa de estudo para discriminação de parâmetros que permitem a interpretação genética de fácies de diamictitos, no sentido de melhor compreender processos glaciais e interpretar condições específicas ocorrentes durante a deposição desses sedimentos. De posse dessas informações, as fácies, então definidas, foram aqui agrupadas em associações de acordo com o relacionamento observado em suas ocorrências, considerando-se a influência glacial na área do estudo no contexto terrestre, marinho de plataforma proximal e marinho de plataforma distal.

A conformação atual do Arco de Ponta Grossa é derivada de movimentos ocorridos principalmente durante o Neojurássico-Eocretáceo; entretanto, a região onde se desenvolveu o referido arco durante o Mesozóico apresentou atuação pretérita, que condicionou a deposição do Subgrupo Itararé, como pode ser depreendido pela disposição das linhas de isoespessuras desse intervalo (Canuto 1985; Santos 1987; Santos et al. 1996).

ÁREA DO ESTUDO A área do estudo é delimitada, ao norte, pela rodovia BR-277, entre as localidades de Witmarsum (PR) e Teixeira Soares (PR), ao sul pela rodovia BR-116, entre as cidades de Quitandinha (PR) e Itaiópolis (SC), e, a leste e oeste, pelas regiões onde ocorrem os limites, inferior e superior, do Subgrupo Itararé, respectivamente com o embasamento cristalino e Subgrupo Guatá, em partes dos Estados do Paraná e Santa Catarina (Fig. 1).

\section{ESTRATIGRAFIA}

Classificação e nomenclatura utilizadas Foi adotada a proposta de Rocha-Campos (1967) de classificação e nomenclatura das sucessões glacial e pós-glacial da Bacia do Paraná, respectivamente como Subgrupo Itararé e Subgrupo Guatá, no Grupo Tubarão, que considera a complexa interrelação e íntima "consanguinidade" dos componentes litológicos do Subgrupo Itararé, potencialmente divisível em formações, e das próprias subdivisões já reconhecidas no Subgrupo Guatá (formações Rio Bonito e Palermo).

Utiliza-se, também, a proposta de Schneider et al. (1974), que subdivide o Subgrupo Itararé em três unidades com hierarquia de formação, correspondendo, 


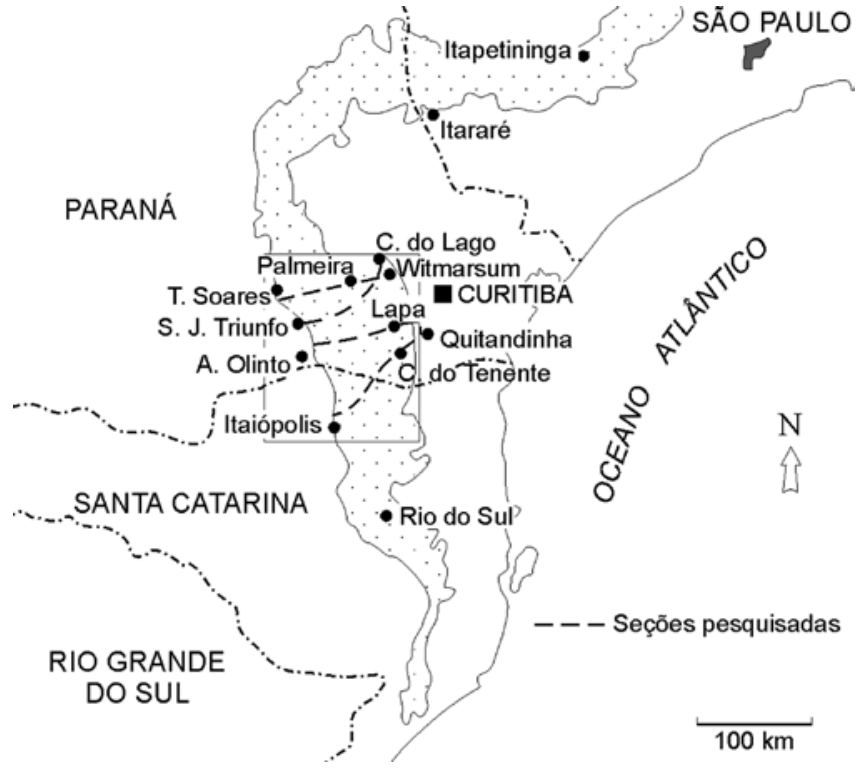

Figura 1 - Localização da área do estudo.

de baixo para cima, às formações Campo do Tenente, Mafra e Rio do Sul, porém dela discordando quanto à denominação de grupos para o que consideramos como Subgrupo Itararé e Subgrupo Guatá.

Seções geológicas estudadas Foram estudadas quatro seções geológicas com cerca de $60 \mathrm{~km}$ de extensão e $700 \mathrm{~m}$ de espessura, de rochas do Subgrupo Itararé, incluídas nas formações propostas por Schneider et al (1974), compondo os perfis Witmarsum-Teixeira Soares (BR-277), Colônia do Lago-Palmeira-São João do Triunfo, Mariental-Lapa-Antonio Olinto (BR-476), todos no Estado do Paraná, e Quitandinha-Campo do Tenente-Itaiópolis (BR-116), no Paraná e em Santa Catarina (Fig. 1).

Os afloramentos examinados, embora não contínuos, compõem perfis estratigráficos da faixa de afloramentos do Subgrupo Itararé (da base até o topo).

MÉTODOS O reconhecimento de fácies no Subgrupo Itararé, no Sul do Paraná e norte de Santa Catarina, fundamentou-se, basicamente, no exame e descrição de afloramentos através de técnicas convencionais de análise de fácies, identificação e interpretação de processos e ambientes sedimentares e feições de abrasão glacial sob a forma de pavimentos estriados formados sobre o embasamento e superfícies estriadas intraformacionais, e interpretação de características e feições dos diamictitos do Subgrupo Itararé.

Os sedimentos expostos foram examinados em cortes de quatro rodovias, que cruzam a faixa de afloramentos do Subgrupo Itararé, ao sul-sudoeste do Arco de Ponta Grossa.

CRITÉRIOS UTILIZADOS NA IDENTIFICAÇÃO DE FÁCIES DE DIAMICTITOS A análise da informação bibliográfica e a experiência de campo que vem sendo adquirida na Bacia do Paraná permitiram discriminar uma série de feições sedimentares e estratigráficas, que vêm se mostrando relevantes para a interpretação de fácies e ambientes de sedimentação dos depósitos glaciogênicos, observadas na quadro 1 .

FÁCIES DE DIAMICTITOS A utilização dos critérios acima levou à definição das fácies, apresentadas a seguir.

\section{FÁCIES DIAMICTITO MACIÇO COMPACTADO}

Características Diamictito síltico-argiloso a arenoso, espessuras de poucos decímetros a um metro, extensão lateral de algumas dezenas de metros em corpos descontínuos de seção "em cunha", geralmente inclinados, prensados e compactados contra irregularidades do substrato de superfície plana, polida, estriada e glaciotectonizada, formada sobre rochas do Pré-Cambriano, sedimentos eopaleozóicos, ou do Subgrupo Itararé.

Próximo à base do diamictito ocorrem intercalações de siltito e arenito e clastos imbricados. Estrias observadas mostram orientação coincidente com o alongamento aparente do topo do substrato; mais raramente ocorrem estrias paralelas na superfície superior do diamictito, indicando recorrência glacial.

Exemplo (Fig. 2): Km 4, BR-116 (após limite PR-SC). Ocorre crista de arenito fino a médio, de topo ondulado, liso e polido, tendo, em seu interior, estruturas sedimentares do tipo gradação interna, marcas onduladas migrantes e alternância de laminação cruzada e lenticular com lâminas de argila; estruturalmente, são observadas dobras fechadas e cruzadas por falhas centimétricas. Por contato discordante, sobrepõe-se diamictito maciço compactado síltico-arenoso "em cunha", com falhas inversas sub-verticais.

Interpretação Estes diamictitos são interpretados como resultantes de processo de alojamento, sob geleira aterrada em ambiente terrestre, onde o arrasto por fricção entre os detritos em tração e o embasamento é maior do que a tensão de cisalhamento imposta pelo gelo em movimento e, portanto, é suficiente para inibir futuros movimentos dos detritos (Benn \& Evans 1998). O depósito assim resultante é denominado till de alojamento, que se preserva, no geral, em irregularidades do substrato onde a pressão normal efetiva exercida pelo gelo e a pressão de fusão do gelo são maiores (Canuto 1985).

Tilitos de alojamento podem ser depositados sob geleira aterrada em ambiente terrestre subaéreo, e sobre substrato em ambiente subaquático.

As evidências desse processo, no exemplo apresentado, são a associação do tilito de alojamento sobre crista de arenito, cujo alongamento local, verificado nos dois lados do corte na rodovia, e seu modo de ocorrência, coincidem com as de depósitos flúvio-glaciais subaquáticos descritos por Rust \& Romanelli (1975), formados a partir de canal subglacial, desembocando em corpo de água.

Outros elementos que reforçam a hipótese de 
Quadro 1 - Critérios utilizados na identificação de fácies de diamictitos.

\begin{tabular}{|c|c|}
\hline CRITÉRIOS & FUNDAMENTOS \\
\hline Estratificação & 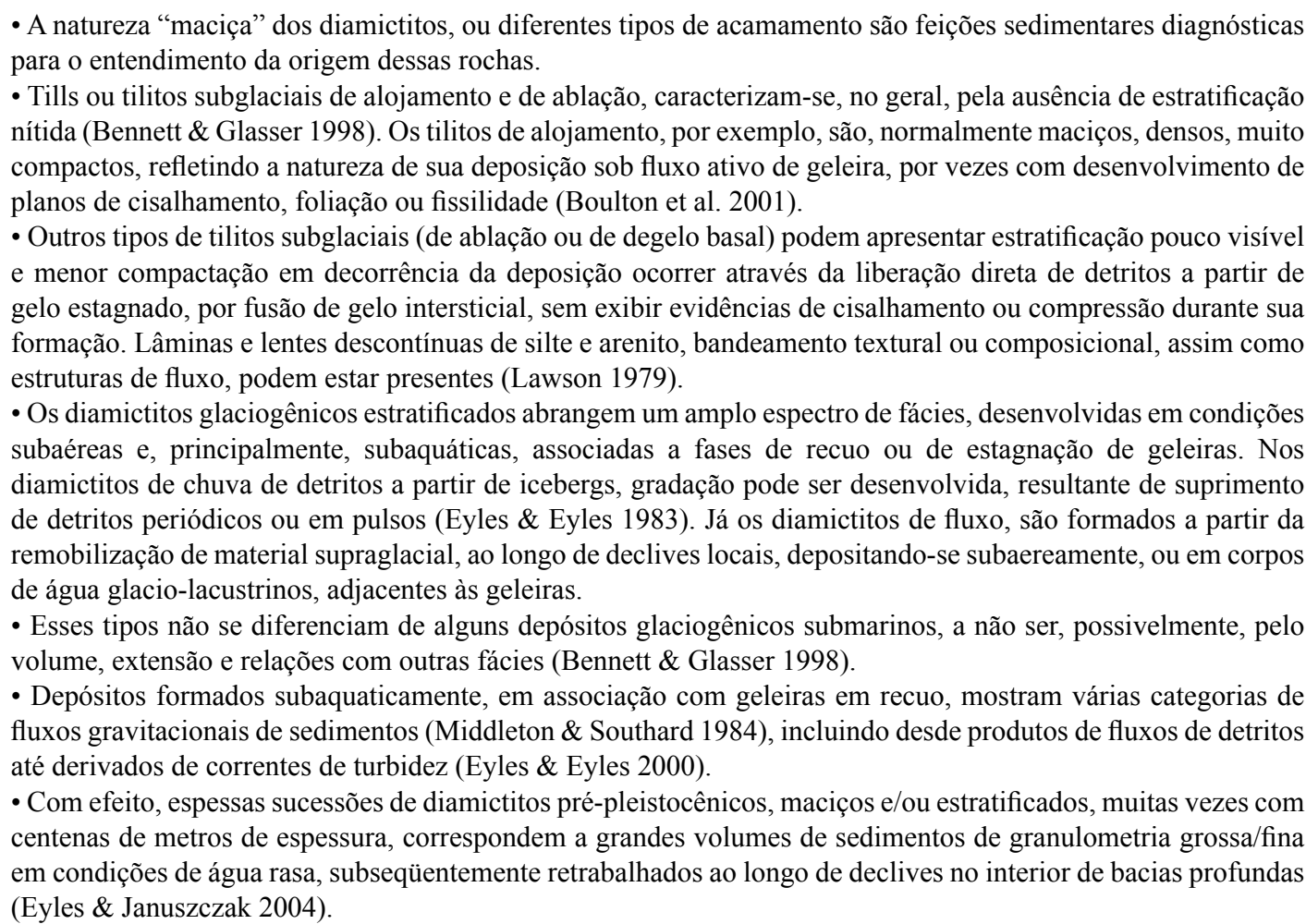 \\
\hline
\end{tabular}

- O termo till de deformação foi introduzido por Elson (1961) para se referir a rochas ou sedimentos inconsolidados destacados de sua posição por cisalhamento subglacial. Mais recentemente (Boulton \& Hindmarsh 1987) percebeu-se que sedimentos podem formar um leito móvel deformável sob geleiras que fluem sobre substratos não consolidados. Essas camadas consistem de sedimentos em estado dúctil, pré-glaciais, que foram sobrepassados e deformados, ou sedimentos glaciais, tills de alojamento e sedimentos flúvio-glaciais, tanto antecedentes, como tendo feito parte da glaciação contemporânea à deformação.

- Deformação glaciotectônica (Boulton \& Hindmarsh 1987; Bennett \& Glasser 1998; Tomio 2004) ocorre quando o esforço imposto por uma geleira excede a resistência de materiais subjacentes ou frontais a ela, que podem estar sujeitos tanto à deformação rúptil (falhas, cavalgamentos) como à deformação dúctil (dobras). A deformação dos sedimentos ocorre em estágios, dependendo da intensidade de deformação ou cisalhamento a que são submetidos pela geleira sobrejacente.

Deformação

- Sedimentos submetidos a níveis muito altos de cisalhamento se tornam completamente misturados e homogeneizados. O produto final, portanto, de uma deformação intensa é um diamicton homogêneo no qual todas as estruturas sedimentares originais do depósito foram destruídas. Esses diamictons recebem a denominação de tills de deformação (Elson 1961).

- Frakes \& Crowell (1969) atentaram para o provável significado de intercalações na interpretação de fácies dos diamictitos na Bacia do Paraná, para a identificação de processos de movimentos de massa a eles associados, causando ressedimentação de corpos dessa litologia.

- Camadas rompidas lateralmente (boudinage sedimentar), dobramentos e contorções diversas (slump overfold) e pseudonódulos são feições comuns em muitos dos diamictitos examinados, não raramente acompanhados de

Intercalações falhas normais ou inversas e de escorregamento (de traço côncavo para cima), e injeção de diques clásticos. Em alguns casos, estas estruturas foram encontradas em associação com deformações de sobrecarga, por exemplo, junto ao contato entre grandes corpos de arenito, sobrepostos a diamictitos.

- Característica avaliada megascopicamente; sua utilidade é limitada, face à possível falta de consistência nas estimativas. Em raros casos notou-se correlação íntima entre granulometria da matriz dos diamictitos, em termos da proporção relativa de areia, silte e argila, e tipos de depósitos. Alguns, interpretados como de fluxos de detritos glaciogênicos, subaquáticos marinhos, mais extensos e espessos, têm matriz síltico-argilosa. Em alguns diamictitos de fluxo, entretanto, predominaram matriz desde arenosa a arenítico-siltosa ou síltico-argilosa. O mesmo parece ocorrer com tilitos subglaciais (de alojamento, de ablação ou de degelo basal), onde a distribuição granulométrica é bi ou multimodal; em tilitos de deformação, a presença de fragmentos íntegros do sedimento original pode provocar marcante variabilidade espacial. 
Quadro 1 - Continuação.

\begin{tabular}{|c|c|}
\hline CRITÉRIOS & FUNDAMENTOS \\
\hline Clastos & $\begin{array}{l}\text { - Observações das características dos clastos, como composição, tamanho, densidade e petrofábrica, não foram feitas } \\
\text { de maneira sistemática. } \\
\text { - No geral, tills e tilitos de alojamento exibem petrofábrica mais definida que tills e tilitos de ablação (Gravenor et al. 1984; } \\
\text { Bennett \& Glasser 1998). Tilitos de alojamento, altamente compactados, tornam difícil a medição dessa propriedade. } \\
\text { - Tills e tilitos de alojamento normalmente apresentam fábrica bem definida na direção do fluxo do gelo e pequeno } \\
\text { desvio na orientação das partículas em relação à fábrica principal. Tills e tilitos de degelo basal também apresentam } \\
\text { mesma característica, mas com pequenas variações, refletindo perturbações atuando em partículas individuais à } \\
\text { medida que se funde o gelo basal. } \\
\text { - Petrofábricas similares às dos tilitos subglaciais ocorrem em fluxos gravitacionais de sedimentos (Anderson et } \\
\text { al. 1991). Segundo Lindsay (1968), o fato relaciona-se com o regime de fluxo, variando de caótica, durante a fase } \\
\text { turbulenta e pouco antes da deposição, a paralela, durante o fluxo laminar. } \\
\text { - Outras características dos clastos, como forma, composição, freqüência, tamanho e feições superficiais, embora, em } \\
\text { parte, úteis, foram observadas apenas esporadicamente. }\end{array}$ \\
\hline $\begin{array}{c}\text { Forma, } \\
\text { espessura e } \\
\text { extensão dos } \\
\text { corpos }\end{array}$ & $\begin{array}{l}\text { - Nos afloramentos examinados, a forma varia de lenticular, ou lobada, a tabular e "em cunha". Formas lobadas } \\
\text { e tabulares (grosseiramente "acanaladas") ocorrem em fluxos gravitacionais de sedimentos (fluxos de detritos e } \\
\text { diamictitos de fluxo). Tills ou tilitos subglaciais tendem a ser tabulares e pouco espessos; tills ou tilitos de alojamento, } \\
\text { entretanto, formam corpos descontínuos, em cunha, emplastados no substrato, deitados ou inclinados sobre bossas } \\
\text { ou cristas do embasamento (Eyles 1983). } \\
\text { - Tills e fluxos de detritos são, no geral, menos extensos que depósitos glacio-marinhos. Diamictitos aqui interpretados } \\
\text { como fluxos de detritos submarinos, variam, em espessura, de decímetros até dezenas de metros, atingindo extensão } \\
\text { mapeável. Entretanto, essas propriedades podem variar grandemente em depósitos subaquáticos da plataforma de } \\
\text { regiões de alta latitude (Benn \& Evans, 1998). }\end{array}$ \\
\hline
\end{tabular}

- Muitas informações, úteis sobre fácies e origem de diamictitos, são obtidas a partir do exame do tipo de relações espaciais apresentadas entre si ou com litologias diferentes.

- Tills continentais ocorrem interdigitados ou recobertos por depósitos fluvio-glaciais ou glacio-lacustrinos, nos quais corpos de arenito e/ou conglomerados apresentam-se confinados em canais, exibindo estruturas sedimentares como estratificação cruzada de grande porte (métrica) (Eyles 1983). Outras fácies associadas a tills ou tilitos terrestres, correspondem a argilitos várvicos e a varvitos glacio-lacustrinos (Ashley 1975), que podem se intercalar em sucessões marinhas, desde que o afluxo de grandes volumes de água de degelo, de geleiras marginais, provoque redução drástica da salinidade, evitando a floculação imediata das argilas (Rocha-Campos et al. 1994).

- Depósitos supraglaciais, como tills de degelo e diamictitos de fluxo, e falhas em sedimentos próximos poderiam indicar deposição em contato com gelo (Gravenor \& Rocha-Campos 1983; Tomio 2004).

- A associação entre diamictitos ou diamictitos e turbiditos, indicativa de origem não glacial para os segundos, é comum na margem continental da Antártica. Segundo Anderson et al. (1991) não se observa ocorrência de tills ou diamictons glácio-marinhos associados com sedimentos marinhos não turbidíticos (lamas marinhas, por exemplo), sendo estes desprovidos de componentes caídos.

Relacões $\quad$ - Tipos de contato inferior e superior são, também, relevantes na diagnose de origem dos diamictitos. Tills/tilitos estratigráficas subglaciais e fluxos gravitacionais de sedimentos apresentam, no geral, contatos inferiores bruscos com o substrato.

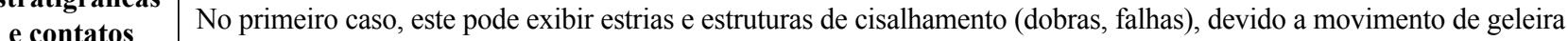
ativa (Rocha-Campos \& Santos 2000; Tomio 2004). Sulcos e estriações erosivas, e estruturas de sobrecarga podem acompanhar os segundos (Eyles \& Eyles 2000). Contatos superiores podem ser, também, bruscos, de tills e tilitos com sedimentos fluvio-glaciais; fluxos de detritos podem exibir contatos bruscos e transicionais com outros sedimentos subaquáticos, como outros tipos de fluxos gravitacionais, ou depósitos glacio-marinhos. Anderson et al. (1991) relatam tills subglaciais em contato brusco com sedimentos glacio-marinhos na plataforma continental antártica.

- Incluem associação de diamictitos com pavimentos ou embasamento e/ou feições periglaciais, como peseudomorfos de cunha de gelo, estruturas de colapso, falhas, depósitos do tipo "pingo", involuções, eskers/kames, e "solo" poligonal (Rocha-Campos et al. 1977; Canuto 1985). Várias dessas feições implicam em deposição subaérea (pseudomorfos de cunhas de gelo e involuções, Canuto 1985), embora haja permafrost e gelo no solo, preservados em sedimentos glaciais na plataforma continental do Ártico, cobertos por transgressão marinha, tornando possível a formação de estruturas, por

Feicões $\quad$ exemplo, de colapso, em decorrência do degelo. Eskers e kames, embora, no geral, típicos de ambiente terrestre, podem geomórficas $\quad$ ocorrer subaquaticamente, adjacentes a geleiras aterradas abaixo do nível do lago ou mar (Carey \& Ahmad 1961). Podem, ainda, ocorrer subaquaticamente feições de abrasão, como estrias, sulcos e até roches moutonnées, como na plataforma continental da Antártica (Anderson et al. 1991).

- Segundo Canuto (1985), fósseis, no geral marinhos (em folhelhos, siltitos e lamitos), ocorrem em diamictitos in situ e ou transportados (mais comuns).

Fósseis • Fósseis devonianos retrabalhados (paleomicroplâncton e esporos) podem dificultar a interpretação, não impedindo, porém, sua utilização como ferramenta, obtendo-se resultados bastante satisfatórios. 


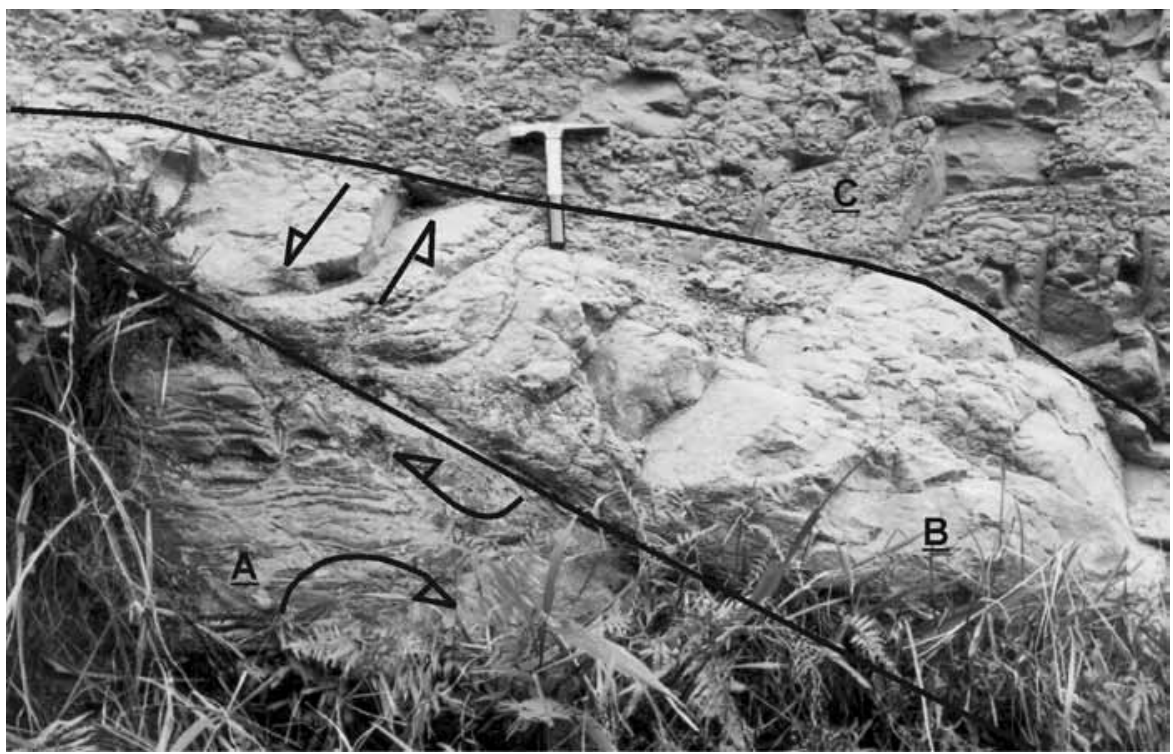

Figura 2 - Diamictito maciço compactado intraformacional. $A=$ Arenito do substrato; $B=$ Cunha de diamictito maciço compactado; $C=$ Diamictito maciço não compactado; Setas = Falhas de cavalgamento e deformações.

origem destes diamictitos referem-se às falhas inversas e foliação encurvada junto à interface entre o diamictito e o substrato.

Feições e modo de ocorrência do diamictito "em cunha" sugerem tratar-se de tilito subglacial de alojamento, sobre embasamento intraformacional modificado pela abrasão e cisalhamento associado ao movimento da geleira.

\section{FÁCIES DIAMICTITO DEFORMADO}

Características Corresponde a camadas móveis deformáveis de sedimentos sob geleiras que fluem sobre substratos inconsolidados (Boulton \& Hindermarsh 1987), formados por detritos preglaciais sobrepassados e deformados, ou detritos glaciais, tills de alojamento e sedimentos flúvio-glaciais, formados anteriormente ou da fase de glaciação contemporânea (Tomio 2004).

A formação de tills de deformação, associando tills de alojamento a quantidades do substrato, faz com que os primeiros possam atingir espessuras maiores que os tills de alojamento, bem como sua extensão lateral.

Exemplo: Colônia Witmarsum, km 154 da BR-277. Diamictito maciço compactado amarelado (em tom claro na Fig. 3), arenoso a síltico-arenoso, sobrepõe-se a sedimentos siluro-devonianos da Formação Furnas. Junto ao contato, partes do diamictito em tom claro apresentam-se quase circunscritas por fragmentos e/ou inclusões até decimétricas avermelhadas (em tom mais escuro na Fig. 3) de arenito do substrato (Formação Furnas), que mostram, também, laminação desenvolvida por cisalhamento na base do diamictito, na zona de contato (Fig. 3). Nesta fácies o diamictito pode apresentar, também, zonas de brechas, formadas por fragmentos de clastos que sofreram processo de trituração, corrugações na matriz contornando clastos e lineações incipientes, a ele laterais.
Interpretação A mistura sedimentar observada na matriz arenosa/síltico-arenosa se deve ao estado plástico do diamictito, submetido à continuidade da sobrepassagem da geleira. As inclusões avermelhadas de arenito foram extraídas da Formação Furnas (substrato). Foliação observada na base do diamictito, junto ao contato com o arenito, formou-se por cisalhamento. À época da sobrepassagem, os sedimentos da Formação Furnas estavam consolidados e emersos, em ambiente terrestre. O diamictito com sedimentos esbranquiçados, antes inclusos no gelo, coletados em outras regiões, ainda inconsolidado, foi deformado, com parte dos clastos esbranquiçados triturados por compressão ao entrarem em contato com fragmentos de rochas da Formação Furnas.

As corrugações observadas na matriz, acompanhando o contorno de clastos decimétricos, e lineações incipientes, a ele laterais, sugerem deformação da matriz por cisalhamento, causado pelo fluxo da geleira, movimentando o clasto para cima e para os lados, onde ocorrem essas estruturas.

O diamictito, interpretado, originalmente, como till de alojamento na sola da geleira ativa (Canuto 1985; 1993), após a deformação, transformou-se em till de deformação. Após ser consolidado, passou a tilito de deformação (Benn \& Evans 1998).

\section{FÁCIES DIAMICTITO MACIÇO NÃO COM- PACTADO}

Características Fácies formada por diamictito maciço, homogêneo, de matriz síltico-arenosa, diretamente sobre tilitos de alojamento ou pavimentos estriados no substrato. Pode apresentar estratificação localizada, com ou sem lentes descontínuas de arenito, siltito e detritos mal selecionados, às vezes com contatos difusos, resultantes da deposição de sedimentos englaciais previamente existentes, de composição, textura, ou cor, 


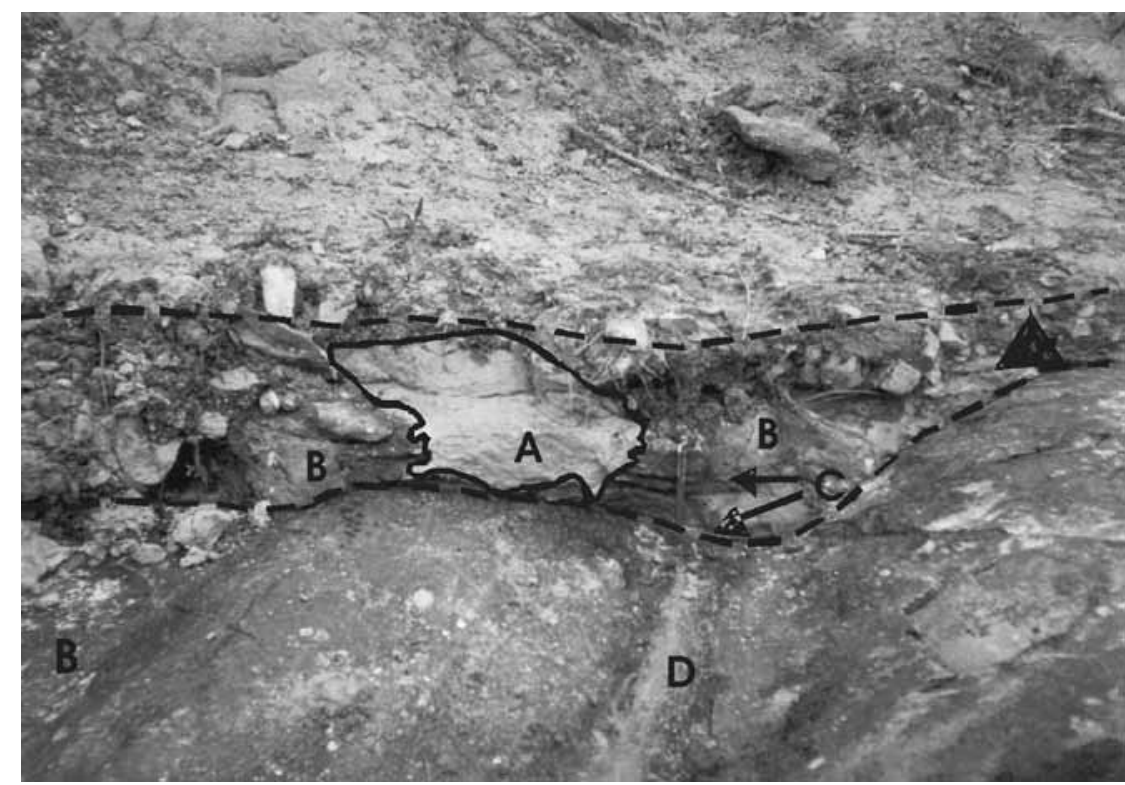

Figura 3 - Diamictito maciço deformado (-); junto ao contato, partes do diamictito em tom claro (A), ocorrem quase circunscritas por inclusões do arenito do substrato (B), onde ocorre, também, laminação por cisalhamento $(C) ; D=$ Caneluras.

distintas dos diamictitos circundantes, podendo se apresentar deformadas. Localmente, ocorre orientação preferencial de clastos.

Forma corpos tabulares extensos e espessos, até decamétricos, podendo ser sobrepostos, por contato transicional, por ritmitos, diamictitos laminados e folhelhos com clastos caídos, ou, por contato brusco, por diamictitos de fluxo.

Exemplo: Km 4 da BR-116 (Figs. 2 e 4), após o limite entre Paraná e Santa Catarina. Diamictito maciço não compactado, com 2 a $4 \mathrm{~m}$ de espessura, sobreposto a tilito de alojamento (em cunha) e, lateralmente, ao substrato, de arenito cisalhado, seguido de diamictito contendo corpos deformados de arenito (Fig. 4).

Interpretação São tilitos de ablação, ou degelo subglacial, de características comparadas às descritas na literatura (Benn \& Evans 1998). Incluem orientação preferencial de clastos paralela ao fluxo do gelo, camadas descontínuas e lentes de sedimento mal selecionado, herdados de detritos englaciais estratificados pré-existentes, com composição, textura ou cor distintas dos diamictitos circundantes. Podem envolver ou se acomodar por compactação diferencial ao redor de clastos maiores. Tills de ablação podem ser deficientes em materiais finos, sílticos, se comparados aos tills de alojamento, devido à menor abrasão sofrida pelos detritos englaciais.

\section{FÁCIES DIAMICTITO TABULAR}

Características Espessuras até decamétricas, macroscopicamente maciços, podem conter camadas estiradas (boudinage), fragmentos de camadas canalizadas deformadas de arenito, por vezes dobradas e falhadas, inclusive em forma de "bolas"; evidências de estratificação formada pela intercalação de várias litologias. Outros podem conter alinhamento de clastos próximo à base.

Exemplo: Km 175 da BR-277, próximo à cidade de Palmeira (Fig. 5). Ocorre diamictito síltico-argiloso, localmente maciço, porém, no geral, estratificado por intercalação de camadas e lentes longas estiradas (boudinage) ou formando dobras redobradas isoladas de arenito, ou até lentes de ritmitos de diamictito e folhelho, onduladas e dobradas. Clastos são raros, até decímetros em diâmetro, ao redor dos quais a estratificação se adapta.

Interpretação Suas características coincidem com descrições da literatura de depósitos de fluxos coesivos de detritos (Shanmugan 2000).

A feição mais notável é o aspecto geral maciço, característica de fluxos de detritos, que implica em mistura e perda mínima, ou nula, de qualquer fração de sedimento durante o movimento da massa sedimentar. A forma tabular é atribuída a fluxos não canalizados, movendo-se livremente sobre talude (Canuto 1993).

\section{FÁCIES DIAMICTITO LENTICULAR}

Características Forma lobos de seção lenticular e aspecto canalizado, centimétricos a decimétricos, em corpos superpostos e coalescidos que, em conjunto, podem formar espessuras superiores a $10 \mathrm{~m}$. Clastos variam de pouco freqüentes a abundantes, arredondados e subangulares, alguns facetados e/ou estriados, em matriz síltico-argilosa. O contato inferior é brusco, enquanto o superior pode ser transicional para folhelhos. Podem ocorrer clastos com orientação paralela aos planos de acamamento dos canais e clastos emergentes no contato entre corpos sobrepostos.

Exemplo: PR-427, afloramento próximo ao acesso para a localidade de Guaiaca. Diamictitos com 


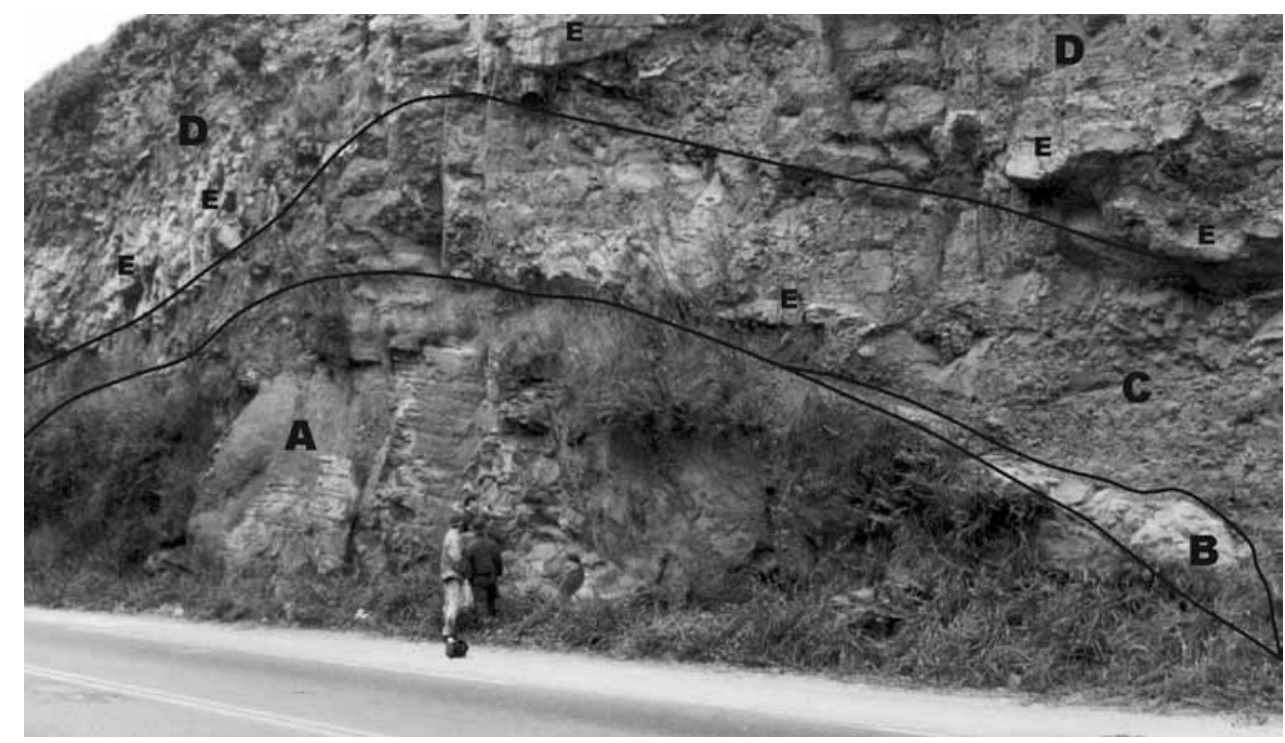

Figura 4 - Afloramento do km 4 da BR-116; $A$ = Arenito do substrato; $B=$ Diamictito maciço compactado; $C$ = Diamictito maciço não compactado; $D=$ Diamictito com inclusões de arenito deformadas; $E=$ Camadas deformadas de arenito.

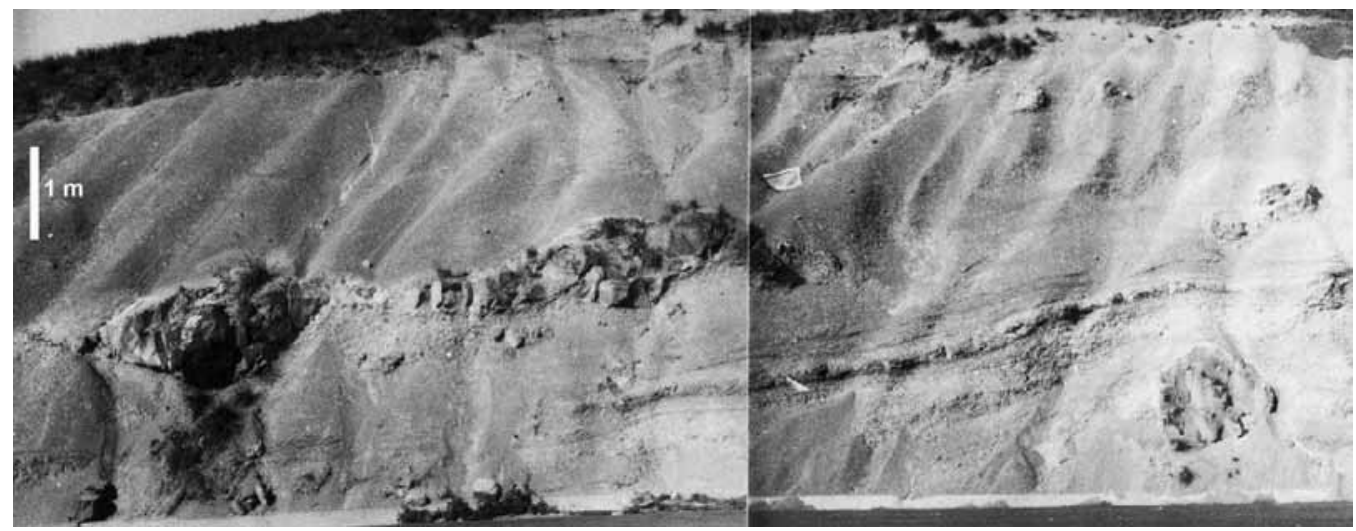

Figura 5 - Diamictito tabular.

geometria em canais amalgamados e superpostos, seção lenticular e aspecto canalizado, centimétricos a métricos (Fig. 6), que, em conjunto, podem formar corpos com espessura superior a $20 \mathrm{~m}$. Apresentam raros a abundantes clastos, centimétricos a decimétricos, arredondados, e subangulares, alguns deles facetados e/ou estriados, em matriz síltico-arenosa. Contato inferior brusco e superior brusco ou transicional para folhelho, siltito ou ritmitos. Localmente ocorre orientação preferencial de clastos paralela aos planos de acamamento.

Interpretação Desenvolvem-se em canais mantendo seu deslocamento ou mudando lateralmente, conforme possíveis irregularidades da superfície do talude ou rampa, resultando em sobreposição e colmatação dos corpos. Ocorrem em patamares mais distais do topo de leques submarinos, em comparação aos diamictitos maciços tabulares, onde a declividade do talude pode ser mais acentuada.

Clastos emergentes paralelos ao contato na in- terface das camadas de diamictito sugerem compactação e/ou rearranjo na massa sedimentar plástica pelo fluxo sobrejacente, por cisalhamento.

São fluxos coesivos de detritos subaquáticos, com características similares às descritas para diamictitos maciços tabulares, distinguindo-se pela geometria dos corpos.

\section{FÁCIES DIAMICTITO LAMINADO COM LEN- TES DE DIAMICTITO MACIÇO}

Características Diamictito laminado, sem variação textural, com ondulações e interrupções por falhas normais a inclinadas e de escorregamento. Envolve lentes alongadas de diamictito maciço e "bolas" de arenito.

Exemplo: Após ponte da RFFSA, próximo ao $\mathrm{km} 63,5$ da BR-476. Zonas descontínuas de diamictito maciço, sobreposto, em contato brusco, por diamictito finamente estratificado ou laminado, com raros clastos (Fig. 7). Laminação por descontinuidades ou juntas subparalelas, sem variação textural associada notável. 


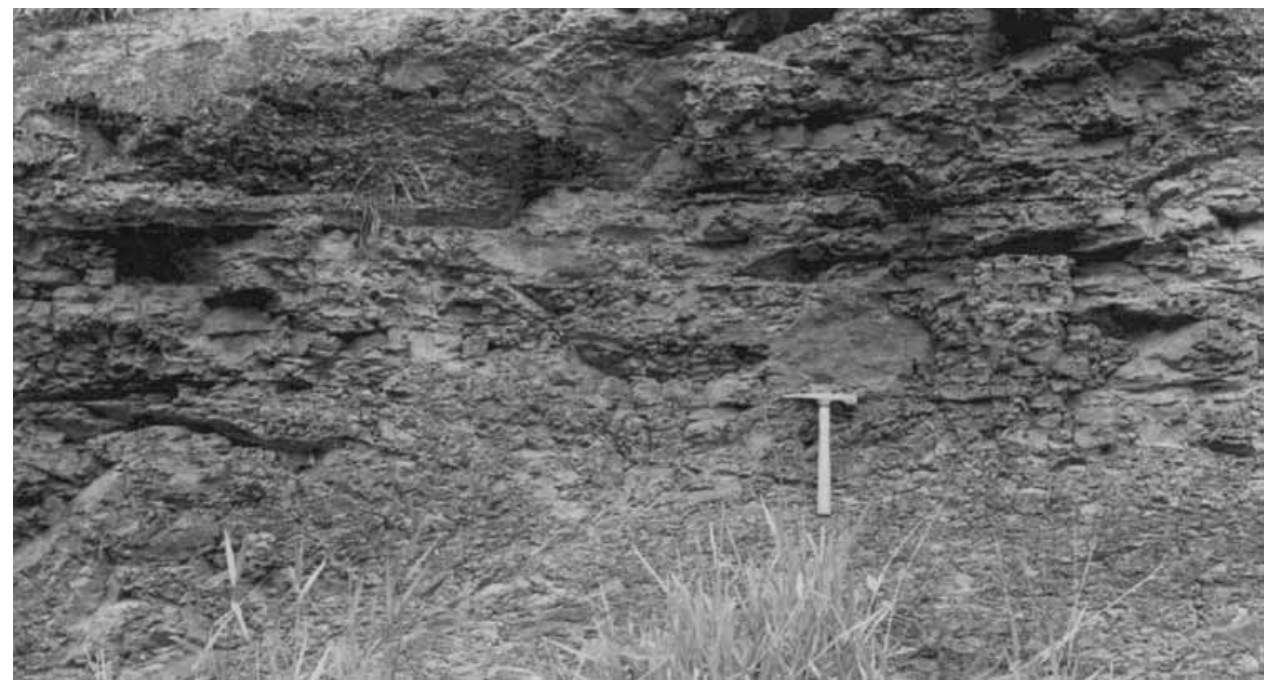

Figura 6-Diamictito lenticular.

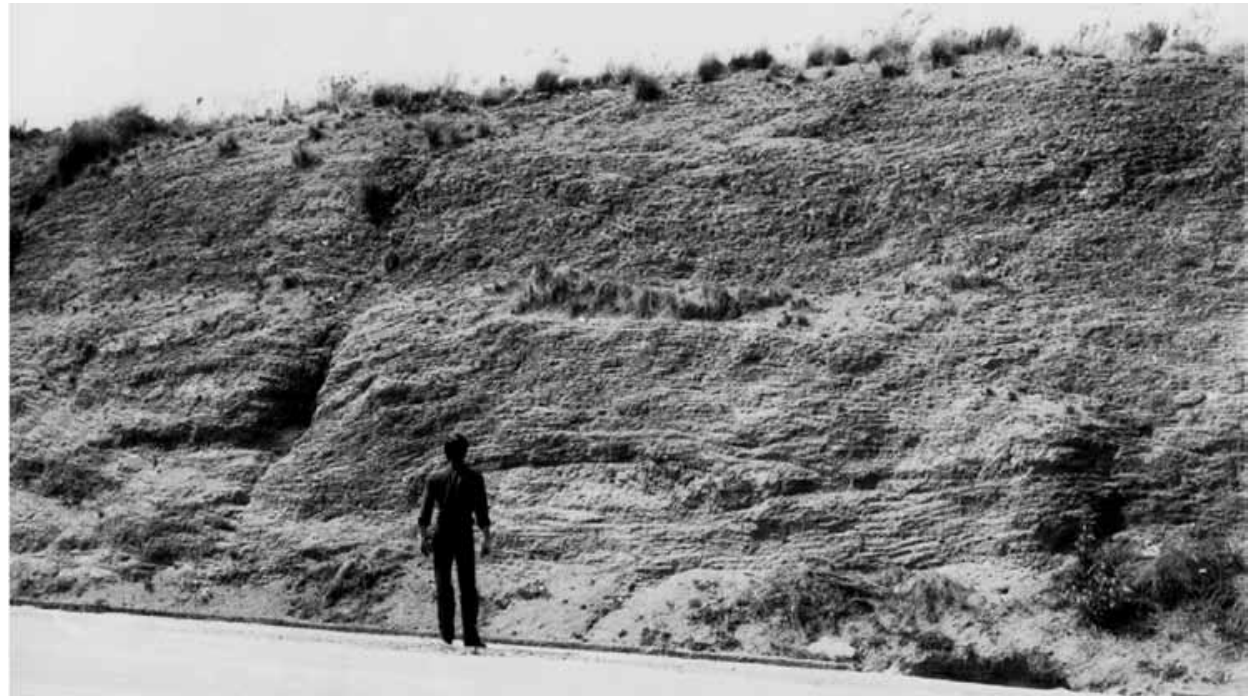

Figura 7 - Diamictito laminado com lentes de diamictito maciço.

Raramente verificou-se alinhamento de clastos pequenos, paralelos à estratificação ondulada ou dobrada, e interrompida por falhas normais, verticais ou inclinadas, e por falhas de escorregamento de traço curvo, normais, envolvendo corpos lenticulares alongados de diamictito maciço, semelhante ao inferior, e "bolas" de areia. O diamictito laminado passa, por transição, no topo, para zona com aspecto várvico.

Interpretação Tilito subglacial, recoberto por diamictito de fluxo e depósitos glácio-marinhos. O deslizamento sobre o tilito teria sido responsável pela mobilização de blocos deste, incorporados à massa que fluiu, a partir da margem do embaciamento local. A foliação do topo do diamictito estratificado sugere deposição subaquática. $\mathrm{O}$ conjunto apresenta-se recoberto, em contato brusco, por depósitos tipicamente subaquáticos, representados pelo arenito e folhelho superiores. A interpretação acima implica em deposição através de fase de avanço, formando-se tilito subglacial, e estag- nação/recuo, depositando-se, então, diamictito de fluxo e depósitos subaquáticos superiores (Canuto 1985).

\section{FÁCIES DIAMICTITO LAMINADO RICO EM CLASTOS}

Características Laminação com muitos clastos sedimentares e do embasamento, alguns com estruturas de deformação em sedimentos subjacentes, côncavas para cima. Alternam-se lâminas de diamictito e siltito argiloso, com ritmicidade várvica, de até dezenas de metros de espessura.

Exemplo: Cerca de $4 \mathrm{~km}$ ao sul de Rio Negrinho, SC, estrada secundária de terra, afloramento no chão (Fig. 8), lateralmente à estrada.

Interpretação Depósito sedimentar intermediário, num espectro que vai de fluxo de detritos a fluxo de turbidez; frequentemente encontrado recobrindo tilitos de ablação. Difere dos fluxos de detritos por ser turbulento e capaz de erodir o substrato, com contato 
superior brusco ou gradacional. Equivale a fluxo glaciogênico denso.

\section{FÁCIES DIAMICTITO ESTRATIFICADO POR VARIAÇÃO TEXTURAL OU INTERCALAÇÕES DE OUTRAS LITOLOGIAS}

Características Corpos extensos e espessos, geometria tabular, grande freqüência de componentes arenosos (Fig. 4, parte superior), lâminas e camadas de diamictito síltico-arenoso a arenoso e arenitos finos a médios interacamados, bem selecionados, com estratificação cruzada, deformados e dobrados, com pequenas falhas de escorregamento.

Exemplo: Km 4 da BR-116, parte superior do afloramento, incluindo foraminíferos arenáceos $(\mathrm{Am}$ modiscus).

Interpretação Produtos de redeposição, por gravidade, em declives ou rampas, provavelmente na parte superior de leques submarinos, compostos de sedimentos glaciogênicos, depositados originalmente junto às margens de corpo de água (Canuto 1985).

Considerando-se os foraminíferos, foram depositados, originalmente, em águas mais rasas; depois, escorregaram em talude mais acentuado. $\mathrm{O}$ contato inferior muitas vezes não é observado, sugerindo ambiente subaéreo ou subaquático. Conforme as características e a comparação com situações da literatura (Postma 1986; Canuto 1985 e 1993; Canuto et al. 2001), esses diamictitos correspondem a fluxos coesivos de detritos.

\section{FÁCIES DIAMICTITO INTERESTRATIFICA- DO COM LITOLOGIAS DIVERSAS CONTENDO ICNOFÓSSEIS}

Características Diamictitos de textura maciça, corpos tabulares decimétricos, espessuras totais de até 40 m e distribuição lateral ampla. Estratificação pouco nítida pela inclusão (lâminas e "filmes") de siltito e folhelho, atravessada por tubos verticais e inclinados de invertebrados preenchidos. São intercalados a folhelhos. Podem apresentar, no topo, superfície coberta por folhelhos com clastos, retrabalhada por invertebrados bentônicos, conforme pistas observadas, representando hiato sedimentar. Clastos emergentes, observados juntamente com as pistas, aparentemente, caíram de gelo flutuante. PR (Fig. 9).

Exemplo: Pedreira da prefeitura de Rio Negro,

Interpretação Diamictitos depositados por sucessivos fluxos de detritos, coalescentes em ambiente subaquático, provavelmente marinho. São diferenciados através de relações estratigráficas com outras litologias e presença de icnofósseis.

FÁCIES RITMITO DE DIAMICTITO E FOLHELHO Características Exemplo: Pedreira de Lapa, km 65,5 da BR-476. Corpos tabulares com espessura de 1 a $4 \mathrm{~m}$, e alternância rítmica de lâminas e camadas de diamictito laminado, ritmito regular de diamictito e folhelho, e folhelho (Fig. 10). O diamictito, o ritmito e o folhelho

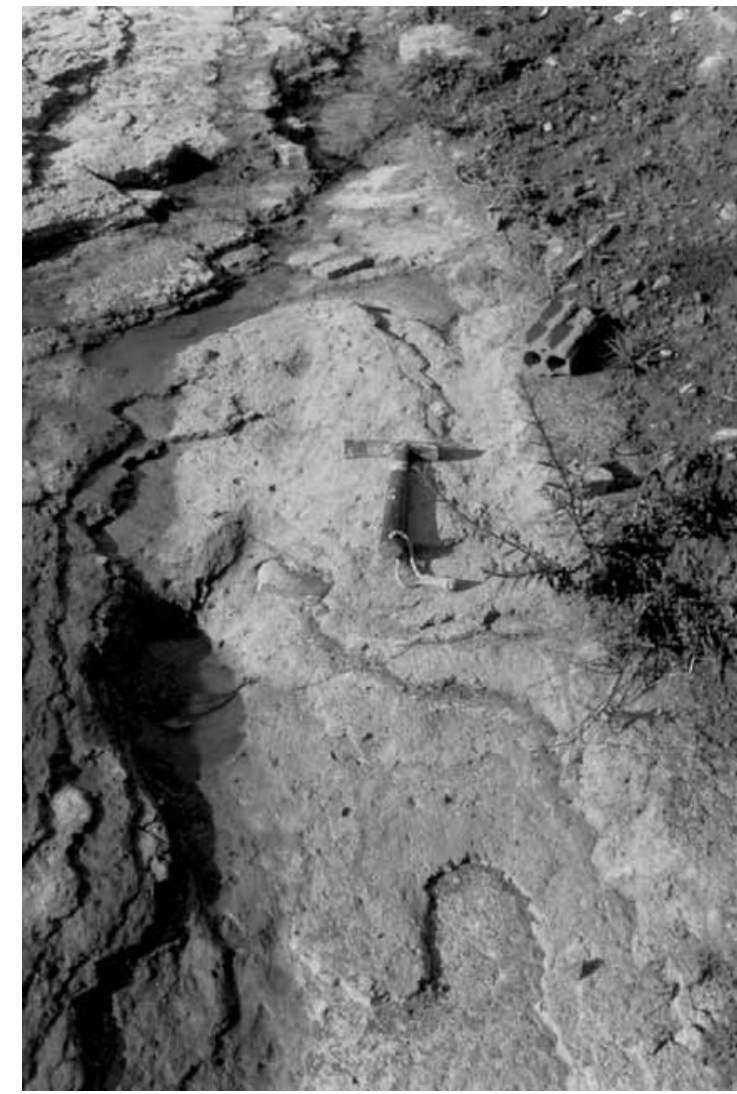

Figura 8-Diamictito laminado rico em clastos.

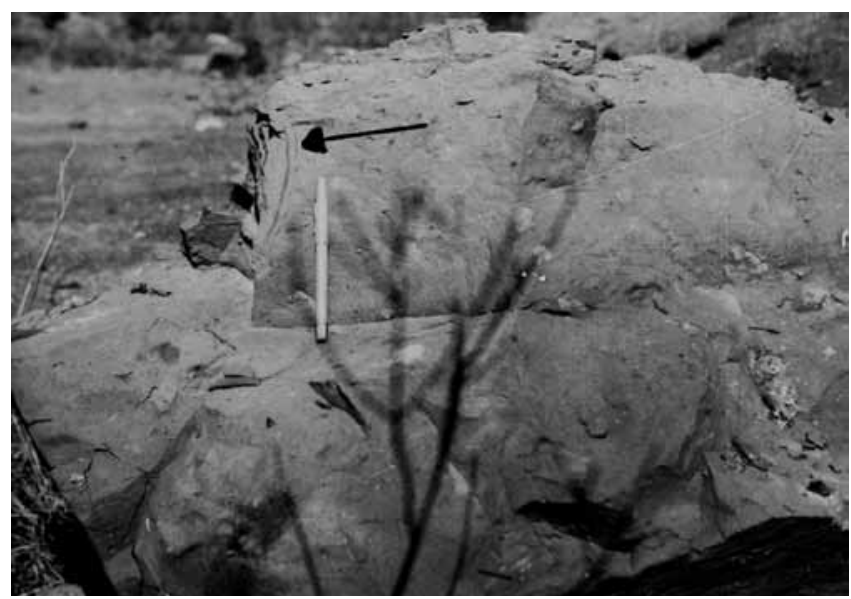

Figura 9 - Diamictito interestratificado com litologias diversas contendo icnofósseis (exemplo indicado pela seta, em forma de tubo vertical).

são ricos em clastos angulares a subarredondados, até decimétricos, a maioria de sedimentos locais, muitos com eixos maiores paralelos à estratificação, em torno dos quais, a matriz parece fluir.

Interpretação Deposição subaquática por gravidade, envolvendo fluxo denso ou de lama, capaz de extrair, incorporar e transportar fragmentos de argila, e 
correntes de turbidez, responsáveis pela formação dos ritmitos, sobrepostos por folhelhos. Clastos caídos na parte superior, estratificada, do diamictito, no ritmito e folhelho, denota a presença de icebergs na bacia local de sedimentação. A sucessão sedimentar representa depósitos de avanço e estagnação/recuo do gelo que, localmente, atingiu a bacia local de sedimentação.

FÁCIES UTILIZADAS NO ESTUDO DE ASSOCIAÇÕES DE FÁCIES A partir da forma de relacionamento verificada entre as 10 fácies reconhecidas no campo, foram determinadas e interpretadas suas associações, apresentadas a seguir.

\section{ASSOCIAÇÕES DE FÁCIES}

Definição de fácies No sentido da conceituação original objetiva (Gressly 1838), uma fácies é um corpo de rocha com características específicas, que o distingue de outras unidades rochosas, ou um "rótulo" (Anderson 1983) que resume a interpretação dos processos de deposição de uma certa unidade de rocha. Onde rochas sedimentares podem ser observadas e manuseadas em afloramentos ou através de testemunhos de sondagem, a entidade é definida com base na cor, acamamento, composição, textura, estruturas sedimentares e fósseis.

O conhecimento do contexto de uma fácies, isto é, a relação entre uma fácies e outras, é essencial antes de se propor uma interpretação ambiental. Considerase que, em última análise, fácies são interpretadas em termos ambientais através das relações com suas vizinhas e, para tanto, devem ser agrupadas em associações admitidas como geneticamente relacionadas (Collinson 1969). Assim, de acordo com Reading \& Levell (1996), as associações de fácies correspondem aos blocos essenciais de construção da análise de fácies e, embora a terminologia possa eventualmente diferir, "grupos" de modelos de associações de fácies têm sido construídos e propostos para a maioria dos ambientes.

Associações de fácies Associações de fácies são grupos de fácies que ocorrem conjuntamente e são consideradas como geneticamente e ambientalmente relacionadas (Reading \& Levell 1996).

Reading \& Levell (1996) exemplificam com conjuntos sedimentares formados por turbiditos espessos intercalados com conglomerados, escorregamentos e lamitos, e, por outro lado, turbiditos finos intercalados apenas com lamitos. Cada um desses grupamentos poderia ser identificado como uma associação de fácies. A associação fornece evidência adicional que torna a interpretação ambiental mais fácil do que tratar cada fácies isoladamente.

Canuto et al. (2001) reconhecerem várias associações de fácies consideradas como diagnósticas, contendo ocorrências estratigráficas próprias e específicas para a determinação de cada associação. Destarte, litofácies registradas em mais de uma associação não foram, então, consideradas como diagnósticas. No primeiro caso, uma fácies pode ocorrer apenas num determinado ambiente, devido a processos particula-

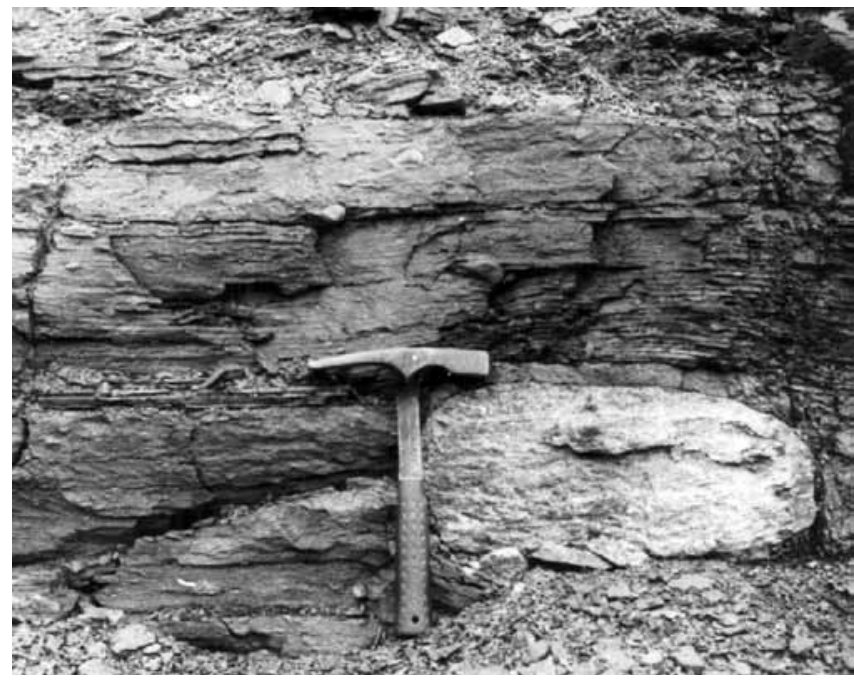

Figura 10 - Fácies ritmito de diamictito e folhelho.

res associados unicamente a esse ambiente, como, por exemplo, tilitos de alojamento. No segundo caso, uma dada fácies pode ocorrer em mais de um ambiente sedimentar, como conseqüência da atuação de um mesmo processo sedimentar. Por exemplo, fluxos gravitacionais de sedimentos podem se desenvolver em ambiente terrestre, como leques aluviais, ou em ambiente lacustre, ou, então, em ambientes marinhos, como componentes de leques submarinos.

Um ambiente sedimentar será determinado mais seguramente associando-se fácies comuns observadas, a uma ou mais fácies diagnósticas que possam estar presentes, podendo ser incluídas, na análise, biofácies, se estas forem identificadas.

A interação de diferentes tipos de ambientes sedimentares que caracteriza a história deposicional de sucessões sedimentares glaciogênicas, ou depositadas sob influência glacial, introduz considerável dificuldade no reconhecimento de associações de fácies geneticamente relacionadas e no seu tratamento sistemático, em termos de sistemas deposicionais (Fisher \& Brown 1972; Santos 1987; Santos et al. 1996; Salvetti 2005).

No caso da deposição sedimentar associada à glaciação, sistemas glaciais podem ser associados a quaisquer dos sistemas continentais ou sistemas marinhos costeiros e marinhos. Um sistema glacial terrestre pode ser relacionado com outros sistemas terrestres glaciais, e os depósitos glácio-marinhos a outras fácies marinhas.

Num sistema glacial continental, algumas associações de fácies, areias e cascalhos de lavagem ou depósitos de loess, podem ocorrer em vários arranjos estratigráficos. Nos ou próximo dos complexos de morainas terminais, fácies flúvio-glaciais e de loess podem dominar. Um sistema glácio-marinho pode também apresentar extensos tills basais, lateralmente adjacentes a, ou recobertos por lamas glácio-marinhas finamente estratificadas, contendo clastos caídos. Turbiditos arenosos podem ocorrer interacamados às lamas estratificadas. 
Rocha-Campos \& Canuto (1983 e 1984) reconheceram três associações de fácies nos sedimentos do Subgrupo Itararé, na área estudada: a) Associação terrestre/de geleira "grounded" (aterrada sobre o substrato); b) Associação de tilitos de fluxo e arenitos deformados; e c) Associação de tilitos glácio-marinhos.

A primeira associação, com tilitos megascopicamente maciços, interpretados como de alojamento, representaria a fácies terrestre de geleira, assentada em substrato rochoso (grounded), caracterizada por depósitos glácio-lacustres, inclusive com varvitos na parte basal das seções examinadas. Esta fácies pode recorrer localmente e seu relacionamento com estruturas de involução demonstra recorrência de avanços de geleiras na bacia.

A segunda associação seria caracterizada por diamictitos e arenitos deformados, às vezes complexamente misturados, exibindo dobras de escorregamento, falhas de diversos tipos e fragmentos de camadas rompidas, feições estas típicas de tilitos de fluxo.

Finalmente, a terceira associação, também contendo diamictitos estratificados, teria resultado de movimentos gravitacionais de massas de sedimentos glaciogênicos, que parecem ter sido retrabalhados e deslocados por escorregamento/fluxo ao longo de taludes, em ambiente subaquático, pelo menos em parte marinho. Esse movimento pode ter ocorrido em massa, ou sob a forma de fluxos viscosos, ou de fluxo denso. Localmente, podem estar associados a arenitos flúvioglaciais, varvito e folhelho marinho, em pequenas subbacias. Porém, deve-se lembrar que, atualmente, as denominações "tilito de fluxo" e "tilito glácio-marinho" não são mais utilizadas, considerando-se que o termo "tilito" é aplicado apenas para sedimentos depositados diretamente pela geleira (Santos 1987). Portanto, a expressão "tilito de fluxo" deve ser modificada para "diamictito de fluxo", pois os sedimentos sofreram processo deposicional relacionado a escorregamento, e "tilitos glácio-marinhos" devem ser chamados, na verdade, de “diamictitos glácio-marinhos", que estão associados a processo de queda de clastos de icebergs ou de plataforma de gelo, sobre folhelhos ou siltitos marinhos e, na continuidade do processo deposicional do dia a dia da bacia sedimentação, são recobertos por estes.

Um maior detalhe atingido nas pesquisas permitiu verificar que, embora a subdivisão faciológica proposta por Rocha-Campos \& Canuto (1983 e 1984) fosse, no geral, válida, não refletia a complexidade da história sedimentar do Itararé, no sul do Paraná e norte de Santa Catarina. Gravenor et al. (1984) descreveram associações de fácies de sedimentos glaciogênicos, formados durante fases de avanço e recuo de geleiras que, em parte, coincidem com as aqui discutidas. Vale notar que as associações abaixo caracterizadas incluem, igualmente, conjuntos de litologias formadas, ao que tudo indica, durante avanços e recuos de geleiras atuantes durante o Paleozóico superior, na área estudada, embora a ênfase da descrição seja sobre os depósitos da fase de expansão do gelo.

Para finalizar esta discussão, no trabalho desen- volvido por Canuto (1985), a abordagem utilizada na discriminação das associações foi um pouco sintética, isto é, é provável que as associações sejam complexas, abrangendo mais de um conjunto de litologias representativas de ambientes distintos. Além disso, a experiência adquirida durante o desenvolvimento deste trabalho mostra que feições citadas na literatura especializada disponível, utilizadas para diferenciar fácies glaciogênicas, não são sempre reconhecíveis ou disponíveis para exame em afloramento. Também se admite que diamictitos glaciogênicos, formados em diferentes circunstâncias ambientais, podem exibir um espectro similar de feições básicas (estruturais, texturais, estratigráficas, etc).

A variação de fácies encontradas na vertical e na horizontal implica em uma distribuição mais ou menos complexa das associações e, portanto, dos ambientes respectivos, na área objeto do estudo. Desta maneira, os modelos de sedimentação glacial que podem ser elaborados e as reconstruções paleogeográficas representam uma média das situações que prevaleceram em cada intervalo de tempo analisado.

Entretanto, a análise de fácies dos diamictitos, aqui apresentada, e as relações estratigráficas destes com outras litologias, as fácies formadas por estes outras litologias, e a junção dos sedimentos glaciais com feições e estruturas diagnósticas, do ponto de vista genético, como, por exemplo, estrias e geometria do embasamento, e depósitos flúvio-glaciais e periglaciais, permitiram reconhecer, de maneira mais segura, associações de fácies indicativas dos vários tipos de ambientes sedimentares registrados na área do estudo, apresentadas a seguir.

ASSOCIAÇÃO DE GELEIRA ATERRADA TERRESTRE Esta associação (equivalente à associação terrestrelou de geleira assentada sobre o substrato, de Canuto 1985) é representada por camadas finas de tilito de alojamento, compactado contra cristas ou vales do embasamento (pré-Cambriano ou siluro-devoniano), ou por corpos tabulares, relativamente pouco espessos formados de tilito de degelo, ou por tilitos de deformação.

O primeiro tipo pode ser sobreposto, em contato brusco, por diamictito maciço, ou de estratificação pouco nítida (tilito de degelo); o segundo tipo pode se dispor em contato lateral, ou recobrir, parcialmente, corpos lineares de arenito conglomerático (do tipo esker) kame) e ser recoberto, também, em contato brusco, por diamictito irregular/regularmente estratificado, que mostra lâminas/camadas onduladas e deformadas, falhas normais, reversas e de escorregamento, e inclusões lenticulares do tilito basal maciço diamictito de fluxo, supraglacial). Esta associação pode ocorrer sobre, ou ser sobreposta por ritmito regular, arenito e folhelho. Fósseis marinhos não foram encontrados. No caso do tilito de deformação, o diamictito foi interpretado originalmente como um till de alojamento depositado na sola da geleira ativa, sobre sedimentos mais antigos expostos subaereamente, os quais, através do processo de sobrepassagem da geleira, foram deformados, misturados a fragmentos do arenito do substrato, e transforma- 
dos em till de deformação; após ser consolidado.

ASSOCIAÇÃO DE GELEIRA ATERRADA EM PLATAFORMA PROXIMAL Esta associação (equivalente à associação de plataforma interna/de geleira assentada sobre o substrato, de Canuto 1985) inclui tilito de alojamento, sobrepondo-se, lateralmente, a corpos lineares de arenito estratificado, ou com marcas onduladas migrantes e estratificação cruzada, com superfície de contato lisa/polida, além de estruturas de cisalhamento no substrato. Inclui, também, tilito de degelo, formado por diamictito delgado ou espesso (decimétrico a métrico), tabular, maciço ou de estratificação pouco visível (tilito de degelo), que recobre arenito ou folhelho, que apresentam, em sua parte superior, um pavimento liso ou polido, ou estriado. Além dos dois primeiros tipos, a associação inclui, também, tilitos de deformação subaquáticos.

Tilitos de alojamento podem ser cobertos por diamictitos e arenitos interacamados, deformados, rompidos e falhados (diamictitos de fluxo/escorregados), conglomerados e arenitos finos, de estratificação cruzada, indicando deposição subaquática. As cristas de arenito podem exibir feições semelhantes às de depósitos de lavagem glacial subaquáticos. Fósseis marinhos ocorrem nos diamictitos, podendo ser comuns em litologias associadas.

Os tilitos de degelo, de outro lado, são recobertos, discordantemente, por folhelhos, ou truncados por corpos de arenito cavalgados. Lateralmente, e na vertical, mostram áreas com laminação mal desenvolvida e inclusões de arenito deformado, ou passam, acima, a ritmitos de diamictito e folhelho, rico em clastos, em sua maioria de sedimentos, e ritmito regular e folhelho contendo clastos caídos.

O tilito de degelo é interpretado como tendo sido depositado na sola da geleira e as camadas deformadas indicam sua deformação por movimentos penecontemporâneos à deposição. Os ritmitos de diamictito e folhelho se formaram subaquaticamente, provavelmente por ação de fluxos densos (slurry); ritmitos regulares e folhelhos representam depósitos de correntes de turbidez e de suspensão.

No caso dos tilitos de deformação, os diamictitos que, originalmente, também foram interpretados como tills de alojamento depositados na sola da geleira ativa, sobre sedimentos mais antigos em ambiente subaquático, foram deformados, juntamente, com esses sedimentos, através de sobrepassagem da geleira, formando-se, então, estruturas de cisalhamento.

Outros tipos de diamictitos estratificados, desta associação, representando diamictitos de fluxo e que, provavelmente, se relacionam com fases de estagnação e recuo do gelo, têm acamamento marcado pela intercalação de filmes e lâminas de siltito/arenito, muitas das quais parecem ter sido cisalhadas ou "esgarçadas", paralelamente à estratificação. Estruturas associadas comuns são dobras recumbentes, e "ganchos" de arenito e siltito. Os corpos de arenito, que podem predominar em certos níveis, apresentam limites inferior e superior bruscos, estratificação e estratos cruzados deformados, estrutura acanalada, além de inclusões irregulares ou esféricas de diamictito. Corpos lineares, longos, descontínuos, de arenitos fluviais, com estratificação, orientados de SE-NW ou N-S e, portanto, paralelos às estrias do embasamento, podem ser equivalentes laterais, mas, também, truncam fácies desta associação. Podem, também, representar depósitos de planície de lavagem, subaéreos ou subaquáticos.

ASSOCIAÇÃO DE PLATAFORMA DISTAL Esta associação (equivalente à associação de plataforma externa/bacial, de Canuto 1985) inclui diamictitos em camadas pouco a muito espessas (até, pelo menos, cerca de $40 \mathrm{~m}$ ), tabulares, mapeáveis, em muitos aspectos semelhantes aos corpos descritos acima, da associação de plataforma interna, exceto pela grande espessura e, possivelmente, pela ausência de cisalhamento, nos sedimentos sobre os quais se assentam. Alguns devem corresponder a fluxos de detritos e ocorrem intercalados com folhelhos contendo fósseis marinhos, ritmitos regulares espessos com clastos caídos grandes (métricos), lamitos e corpos tabulares extensos, e relativamente espessos, de arenito fino.

A distribuição dessas fácies pode ser controlada pela presença de sub-bacias mais profundas, com paleodeclives mais abruptos do embasamento (Canuto 1985 e 1993; Santos 1987). A ocorrência de uma seção espessa de ritmitos regulares, possíveis varvitos, indica influxo de grandes volumes de água de degelo na área deposicional.

OCORRÊNCIA Para efeito de localização das associações nos diferentes níveis da coluna estratigráfica do Itararé, foi utilizada a subdivisão do Subgrupo, proposta por Schneider et al. (1974), nas formações, da base para o topo, Campo do Tenente, Mafra e Rio do Sul (Fig. 11).

A associação de geleira aterrada terrestre (AGAT) tende a predominar na base do Subgrupo, Formação Campo do Tenente, que pode, também, incluir fácies pertencentes à associação de geleiras aterradas em plataforma proximal (AGAPP). A esse respeito, vale lembrar a ocorrência de uma série de áreas estreitas de sedimentação mais espessa, alongadas, orientadas de SE-NW, que se estendem da atual margem rumo ao centro da bacia. Essas feições são, aproximadamente, paralelas às estrias sobre o embasamento $\mathrm{e}$, portanto, sugestivas de vales pré-glaciais, fluviais, ou, até, tectônicos, modificados pela erosão glacial.

A associação de geleiras aterradas em plataforma proximal (AGAPP) é registrada ao longo de toda a coluna estratigráfica, em todas as seções estudadas.

A associação de plataforma distal (APD) é comumente encontrada nas Formações Mafra e Rio do Sul, embora possa ser, também, observada no extremo superior da Formação Campo do Tenente.

Feições geomórficas dos sedimentos associados com diamictitos da parte superior da coluna estratigráfica, não obstante, podem sugerir recorrência da asso- 


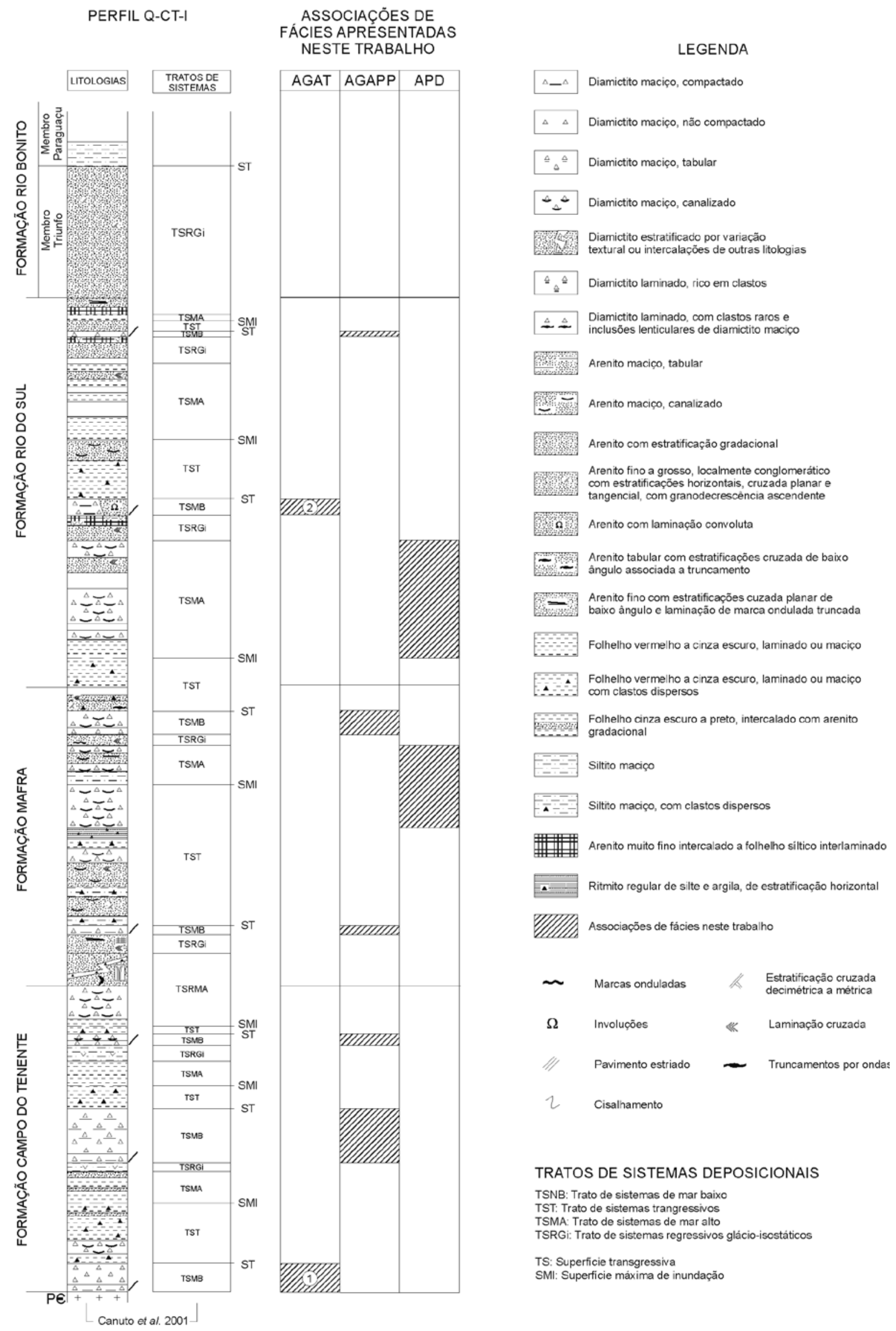

Figura 11 - Ocorrência das associações de fácies no perfil Q-CT-I e suas relações com litologias e tratos de sistemas deposicionais definidos por Canuto et al. (2001); (1) e (2) representam, respectivamente, ocorrência e recorrência da associação de geleira aterrada terrestre. 
ciação de geleira aterrada terrestre, na Formação Rio do Sul, fato verificado na seção Q-CT-I.

CONCLUSÕES As associações não são de ocorrência restrita a qualquer parte da coluna estratigráfica do Subgrupo Itararé, podendo, até, se alternar, em alguns casos.

Embora tenham sido analisadas 4 seções geológicas, a impossibilidade de inclusão de encartes no artigo restringiu a apresentação dos resultados a apenas uma das seções, a qual, porém, é suficientemente representativa dos mesmos.

A figura 11 mostra a coluna estratigráfica do Subgrupo Itararé, representada, na área do estudo, pela seção colunar relativa à seção geológica QuitantinhaCampo do Tenente-Itaiópolis, e o arcabouço seqüencial de $3^{\mathrm{a}}$ ordem definido por Canuto et al. (2001), associados a colunas demonstrativas das ocorrências das associações de fácies caracterizadas sob a ótica deste trabalho.

Verifica-se que, na coluna estratigráfica do Subgrupo Itararé, a associação de geleira aterrada terrestre se localiza, normalmente, abaixo de tratos de sistemas transgressivos (Canuto et al. 2001), considerando-se que suas características deposicionais terrestres, incluindo tilitos de alojamento e feições periglaciais, se associam a épocas de mar baixo.

A associação de geleira aterrada em plataforma proximal, por também envolver tilitos de alojamento, fato que a coloca em contexto glacial proximal, que se desenvolve paralelamente a épocas de mar baixo, também se localiza estratigraficamente abaixo de tratos de sistemas transgressivos.

A associação de plataforma distal é registrada, estratigraficamente, sempre acima de tratos de sistemas transgressivos (Canuto et al. 2001), ou em parte deles, já em fase transgressiva tardia, relacionada a aprofundamento do nível relativo do mar. As espessas ocorrências de diamictititos desta fácies, localizadas em contextos de tratos de sistemas transgressivos e de mar alto (Canuto et al. 2001), sugerem desenvolvimento a partir de fluxos gravitacionais de diamictitos, originalmente depositados em áreas mais elevadas de talude em forma de tilitos de ablação, fluxos esses disparados por desestabilização dos sedimentos devido a se tornarem encharcados com a elevação do nível relativo do mar.

A coluna estratigráfica referente à seção geológica W-P-TS não apresenta associação de geleira aterrada terrestre (AGAT) por ser representativa de região marinha mais distal (AGAPP e APD), localizada mais ao norte na área do estudo, diferentemente do que ocorre na seção geológica Q-CT-I, incluindo épocas de sedimentação continental (AGAT).

Agradecimentos A Fundação de Amparo a Pesquisa do Estado de São Paulo, FAPESP, pelo apoio financeiro ao projeto $\mathrm{N}^{\circ}$ 97/13.973-2 e apoio financeiro parcial, através do projeto $\mathrm{N}^{\circ}$ 04/14.616-4, a Ian McReath, pela revisão do Inglês efetuada no Abstract, e a Marco Antonio Netto Chamadoira, da Seção de Ilustração Geológica, pela participação na confecção dos desenhos.

\section{Referências}

Anderson J.B. 1983. Ancient glacial-marine deposits: their spatial and temporal distribution. In: Molnia B.F. (ed.) Glacial-Marine Sedimentation. New York and London, Plenum Press, p. 3-92.

Anderson J.B., Kennedy D.S., Smith M.J., Domack E.W. 1991. Sedimentary facies associated with Antarctica's floating ice masses. Geological Society of America, Special Paper 261:1-25.

Ashley G.M. 1975. Rhythmic sedimentation in glacial Lake Hitchcock, Massachusets-Connecticut. In: Jopling A.V. \& McDonald B.C. (eds.) Glaciofluvial and glaciolacustrine sedimentation. Society of Economic Paleontologists and Mineralogists, Special Publication, 23:304320.

Benn D.I. \& Evans D.J.A. 1998. Glaciers and glaciation. Great Britain, Arnold Publishers, 734 p.

Bennett M.R. \& Glasser N.F. 1998. Glacial Geology. Ice Sheets and Landforms. New York, John Wiley \& Sons.

Boulton G.S. \& Hindmarsh R.C.A. 1987. Sediment deformation beneath glaciers; interactions between sediment flow and drainage and geological products. Journal of Geophysical Research, 92(B2):9059-9082.

Boulton G.S., Dobbie K.E., Zatsepin S. 2001. Sediments deformation beneath glaciers and its coupling to the subglacial hydraulic system. Quaternary International, 86:3-26.
Canuto J.R. 1985. Origem dos diamictitos e de rochas associadas do Subgrupo Itararé, no sul do Estado do Paraná e norte do Estado de Santa Catarina. Dissertação de Mestrado, IGc, Univ. de São Paulo, São Paulo, 187 p.

Canuto J.R. 1993. Facies e ambientes de sedimentação da Formação Rio do Sul (Permiano), Bacia do Paraná, na Região de Rio do Sul, Estado de Santa Catarina. Tese de Doutoramento, IGc, USP, São Paulo, 164 p.

Canuto J.R., Santos P.R., Rocha-Campos A.C 2001. Estratigrafia de seqüências do Subgrupo Itararé (Neopaleozóico) no leste da Bacia do Paraná, nas regiões sul do Paraná e norte de Santa Catarina, Brasil. Revista Brasileira de Geociências, 31(1):107-116.

Carey S.W. \& Ahmad N. 1961. Glacial marine sedimentation. In: Raasch G.O. (ed.) Geology of the Arctic. Toronto University Press, Toronto v.2, p. 865-894.

Collinson J.D. 1969. The sedimentology of the Grindslow Shales and the Kinderscout Grit: a deltaic complex in the Namurian of northern England. Journal of Sedimentary Petrology, 39:194-221.

Dreimanis A. 1988. Till, their genetic terminology and classification. In: Goldthwait R.P. \& Matsch C.L. (eds.) Genetic classifications of glacigenic deposits. Bolkema, Rotterdam, p. 17-84.

Elson J.A. 1961. Geology of tills. of the Canadian Conference on Soil Mechanics, 14, Proceedings Section 3, p. 
$5-17$.

Eyles N. 1983 (ed.) Glacial Geology: An Introduction for Engineers and Earth Scientist. Oxford, Pergamon Press, $431 \mathrm{p}$.

Eyles N., Carolyn H.E., Miall A.D. 1983. Lithofacies types and vertical profile models; an alternative approach to the description and environmental interpretation of glacial diamict and diamictite sequences. Sedimentology, 30:393-410.

Eyles C.H. \& Eyles N. 2000. Suaqueous mass flow origin for Lower Permian diamictites and associated facies of the Grant Group, Barbwire Terrace, Canning Basin, Western Australia. Sedimentology, 47(2):343-356.

Eyles N. \& Januszczak N. 2004. "Zipper-rift”: a tectonic model for Neoproterozoic glaciations during the breakup of Rodinia after 750 Ma. Earth-Science Reviews, 65: $1-73$.

Fisher W.L. \& Brown L.F. 1972. Clastic depositional systems - A genetic approach to facies analysis. Austin, Bureau of Economic Geology University of Texas, $211 \mathrm{p}$.

Frakes L.A. \& Crowell J.C. 1969. Late Paleozoic glaciation: I, South America. Geological Society of America Bulletin, 80:1007-1042.

Gravenor C.P. \& Rocha-Campos A.C. 1983. Patterns of Late Paleozoic Glacial Sedimentation on the Southeast Side of the Parana Basin. Palaeogeography, Palaeoclimatology, Palaeoecology, 43(1):1-39.

Gravenor C.P., Von Brunn V., Dreimanis A. 1984. Nature and classification of waterlain glaciogenic sediments, exemplified by Pleistocene, Late Paleozoic and Late Precambrian deposits. Earth-Science Reviews, 20:105166.

Gressly A. 1838. Observations géologiques sur le Jura Soleurois. Newe Denkschr. Allg. Schweiz, Ges. Ges. Naturw., 2:1-112. 2.2.1.

Kellog T.B. \& Kellog D.E. 1981. Pleistocene sediments beneath the Ross Ice Shelf. Nature, 293:130-133.

Lawson D.E. 1979. A comparison of the pebble orientations in ice and deposits of the Matanuska Glacier. Alaska. Journal of Geology, 87:629-645.

Lindsay J.F. 1968. The development of clast fabric in mudflows. Journal of Sedimentary Research, 38(4):12421253.

Middleton G.V. \& Southard J.B. 1984. Mechanics of sediment movement. Society of Economic Paleontologists and Mineralogists, Short Course 3, 401.

Paul M.A. \& Eyles N. 1990. Constraints of the preservation of diamict facies (melt-out tills) at the margins of stagnant glaciers. Quaternary Science Review, 9:51-69.

Postma G. 1986. Classification for sediment gravity-flow deposits based on flow conditions during sedimentation. Geology, 14:291-294.

Reading H.G. \& Levell B.K. 1996. Controls on the sedimentary rock record. In: Reading H.G. (ed.) Sedimentary Environments: Processes, Facies and Stratigraphy, $3^{\text {rd }}$ ed, Oxford, Blackwell Science, p. 5-36.

Rocha-Campos A.C. 1967. The Tubarão Group in the Brazilian portion of the Paraná Basin. In: Bigarella J.J., Becher R.D., Pinto I.D. (eds.) Problems in Brazilian
Gondwana Geology. Curitiba, Universidade Federal do Paraná, 27-102.

Rocha-Campos A.C. \& Canuto J.R. 1983. Fácies and sedimentary environments of Late Paleozoic diamictites and associated rocks in Southern Paraná and Northern Santa Catarina, Brazil. Anais da Academia Brasileira de Ciências, 55(1):138.

Rocha-Campos A.C. \& Canuto J.R. 1984. Involução e outras feições glaciais do Subgrupo Itararé no norte de Santa Catarina. Anais da Academia Brasileira de Ciências, 56(1): 111.

Rocha-Campos A.C. \& Santos P.R. dos 2000. Ação Geológica do Gelo. In: Teixeira W., Toledo M.C.M., Fairchild T.R., Taioli F. (eds.) Decifrando a Terra. Oficina de Textos, p. 215-246.

Rocha-Campos A.C., Saad A.R., Santos P.R., Oliveira M.E.C.B. 1977. Algumas feições periglaciais do Subgrupo Itararé (Neopaleozóico), no Estado de São Paulo. Boletim IG-USP, Série Científica, 8:55-56.

Rocha-Campos A.C., Santos P.R. \& Canuto J.R. 1994. Ice scouring structures in Late Paleozoic rhythmites, Paraná Basin, Brazil. Earth's Glacial Record., p. 234-240.

Rust B.R. \& Romanelli R. 1975. Late Quaternary subaqueous outwash deposits near Ottawa, Canada. In: Jopling A.V \& McDonald B.C. (eds.) Glaciofluvial and glaciolacustrine Sedimentation. Soc. Econ. Paleontol. Miner. Spec. Publ., 23:177-192.

Salvetti R.A.P. 2005. Sistemas Deposicionais e Paleogeografia do Subgrupo Itararé (Neopaleozóico da Bacia do Paraná), na região entre Itu e Indaiatuba, SP. Dissertação de Mestrado, Instituto de Geociências, USP, São Paulo, 116p.

Santos P.R. 1987. Fácies e evolução paleogeográfica do Subgrupo Itararé/Grupo Aquidauana (neopaleozóico) na Bacia do Paraná, Brasil. Tese de Doutoramento, IGc, Universidade de São Paulo, São Paulo, 128 p.

Santos P.R., Rocha-Campos A.C., Canuto J.R. 1996. Patterns of late Palaeozoic deglaciation in the Paraná Basin, Brazil. Palaeogeogr., Palaeoclimatol., Palaeoecol., 125:165-184.

Schneider R.L., Muhlmann H., Tommasi E., Medeiros R.A., Daemon R.F., Nogueira A.A. 1974. Revisão estratigráfica da Bacia do Paraná. In: SBG, Congresso Brasileiro de Geologia, 28, Porto Alegre, Anais, 1: 41-65.

Shanmugam G. 2000. 50 years of the turbidite paradigm (1950s-1990s): deep-water processes and facies models - a critical perspective. Marine and Petroleum Geology, 17:285-342.

Tomio A. 2004. Estilos de deformações glaciotectônicas no Subgrupo itararé, neopaleozóico da Bacia do Paraná. Tese de Doutoramento, Instituto de Geociências, Universidade de São Paulo, São Paulo, 219 p.

Visser J.N.J. 1983. Glacial-marine sedimentation in the Late Paleozoic Karoo Basin, Southern África. In: Molnia B.P. (ed.) Glacial-marine sedimentation. New York, Plenum Press, p. 667-701.

Manuscrito ID 14787

Submetido em 15 de julho de 2009 Aceito em 10 de fevereiro de 2010 